\title{
Advances in friction stir welding by separate control of shoulder and probe
}

\author{
M. Grätzel ${ }^{1}(1) \cdot$ F. Sieber $^{1}$ • K. J. Schick-Witte ${ }^{1}$ - J. P. Bergmann ${ }^{1}$
}

Received: 4 September 2020 / Accepted: 20 April 2021 / Published online: 15 July 2021

(C) The Author(s) 2021

\begin{abstract}
Friction stir welding (FSW) has developed into a reliable and increasing used industrial joining technology. Various tool configurations can be used for FSW, each of which has advantages and challenges. State-of-the-art FSW employs various tool configurations, including the conventional, the stationary shoulder, and the dual-rotational configuration which is characterized by separate control of shoulder and probe. In this study, an innovative method to combine various tool configurations was developed by a novel FSW spindle stack construction. With an additional servomotor, existing FSW systems can be extended by separate control of shoulder and probe so that varying rotational speeds and rotational directions can be set. This allows enhanced possibilities (a) to adjust frictional heat generation and (b) to apply several tool configurations. The main advantages of this enhanced type of FSW are demonstrated in three ways: increased weld penetration depth, reduction of undesirable machine vibrations, and the combination of varying tool configurations such as stationary shoulder and conventional FSW. The investigations were carried out with 2-mm EN AA 5754 H22 sheets and performed on a robotized FSW setup.
\end{abstract}

Keywords Friction sir welding $\cdot$ Force reduction $\cdot$ Tool configurations $\cdot$ Dual rotation

\section{Introduction}

Global challenges require the implementation of energy efficient manufacturing methods and economical concepts to preserve natural resources. Therefore industrial applications increasingly consider methods such as additive manufacturing or lightweight design, which are promising technological approaches to meet prospective economical and ecological aspects $[1,2]$. However, the usage of lightweight design also requires the development of appropriate joining technologies such as FSW. The operating principle of this solid state joining technology is based on a wear-resistant welding tool which plasticizes the materials due to frictional heat. During the FSW process, the joining temperatures are below the material's solidus curve so that weld seam irregularities such as

Recommended for publication by Commission III - Resistance Welding, Solid State Welding, and Allied Joining Process

M. Grätzel

info.fertigungstechnik@tu-ilmenau.de

1 Department of Production Technology, Technische Universität Ilmenau, Ilmenau, Germany pores and hot cracks may be prevented due to the absence of a melting bath [3-5]. But FSW is simultaneously affected by process related challenges such as high process forces, tool wear, and comparative low welding speeds [6-8]. Hence economical aspects such as high costs for large FSW setups, preventative tool replacement, and comparatively low welding speeds restrict the application of FSW. Furthermore, industrial demands increasingly require adjustment of the weld seam conditions, so that high mechanical strength and low surface roughness ensure a high-quality joint and fewer or no surface finishing steps [9, 10]. Both mechanical strength and surface conditions are related to the tool configuration. Figure 1 depicts typical tool configurations for performing FSW.

The conventional configuration (Fig. 1a) is known for a simple design and process handling, in which the shoulder and probe have the same rotational speed and direction ( $\mathrm{n}_{\text {probe }}$ $=\mathrm{n}_{\text {shoulder }}$. This simplicity has made it the most commonly used configuration in FSW despite the rough periodic surface structures and inferior mechanical fatigue properties [3, 11]. Recent investigations are extensive and pointing thematic priorities such as weld seam properties of similar and dissimilar materials, varying probe/shoulder geometries, tool wear, and the interactions between tool and FSW setup $[4,6,7,12,13]$. 
Fig. 1 Varying tool configurations for the usage of FSW: a conventional, b stationary shoulder, and $\mathbf{c}$ dual rotation
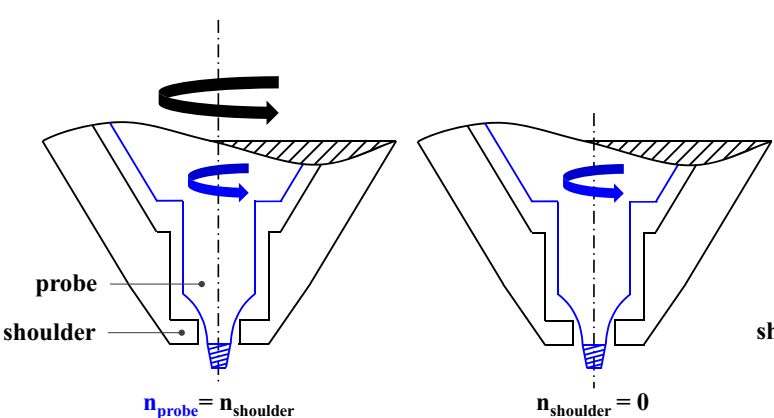

b)

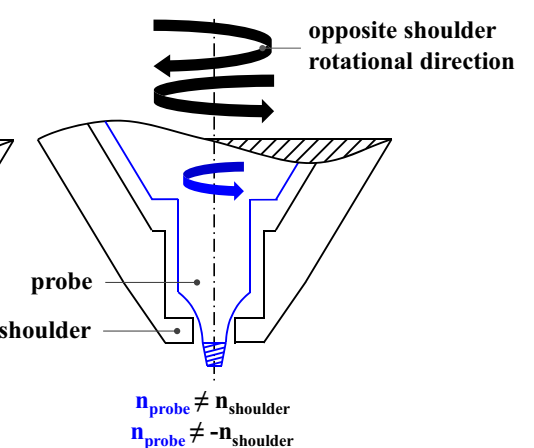

c)
Stationary shoulder is a special configuration of FSW in which the shoulder is fixed. Only the probe rotates and generates the total frictional heat input $\left(\mathrm{n}_{\text {shoulder }}=0\right.$, compare Fig. 1b) [11]. Due to the absence of the shoulder generated heat input, comparatively higher probe rotational speeds are necessary. The stationary shoulder can be used to decrease process forces due to less material being displaced. Furthermore, a relative reduction of the surface roughness may be achieved due to the fact that the fixed shoulder smooths the surface across the weld seam [10]. However, the stationary shoulder configuration requires high demand in process handling. This means in particular the upward material flow in the stationary shoulder, which features a drain movement from the process zone through the gap between the probe and stationary shoulder up to a designated outlet port [9]. Current investigations with stationary shoulder configuration focus mostly the mechanical and physical weld seam properties $[11,14,15]$.

The dual-rotational configuration, in which the shoulder and probe may have different, independent rotational speeds and directions $\left(\mathrm{n}_{\text {probe }} \neq \mathrm{n}_{\text {shoulder }}\right.$ and $\mathrm{n}_{\text {probe }} \neq-\mathrm{n}_{\text {shoulder }}$, compare Fig, 1c), is currently the least used configuration. Initial investigations with the dual-rotational configuration were carried out by Li et al. who mainly focused on the mechanical properties of AA2219-T6. It was demonstrated that an opposite rotational direction and varying welding speeds affect the grain size in the different weld seam zones (zone, heataffected zone, weld nugget zone, and thermo-mechanically affected zone) and the microhardness. Furthermore, an increase of the tensile strength was found due to higher welding speeds and the elimination of flash defects. The consistent rotational speed of shoulder and probe was $800 \mathrm{1} / \mathrm{min}$ [16]. Furthermore, in three-dimensional numerical simulations, the heat generation and temperature distribution were investigated by Shi et al. It was found that the difference of heat generation rate between the advancing side (AS) and retreating side (RS) owing to the difference of relative velocity is weakened so that increased mechanical properties may be achieved due to a process parameter adjustment. The rotational speed considered was in the range of 800-1200 rpm for varying rotational directions [17]. A further advantage of the dual-rotational configuration was reported by Thomas et al. They discussed how the separate control of shoulder and probe may prevent over-heating effects on the outer shoulder edges. During the investigations they used rotational speeds of $5841 / \mathrm{min}$ and $2191 / \mathrm{min}$ for probe and shoulder, respectively [18]. They detected decreased joining temperatures compared to conventional FSW in the heat-affected zone (HAZ), which positively affects the microhardness (reduced material softening). The dual-rotational configuration and the rotational speed of the probe were also investigated by Montazerolghaem et al. They demonstrated that the onion ring nugget shape increases at higher probe rotational speeds. They concluded that dualrotational configuration can be used for controlling the heat input and for the shape of the weld zone manipulation. During the investigation they set rotational speeds of up to $14001 / \mathrm{min}$ and $16501 / \mathrm{min}$ for shoulder and probe, respectively [19]. Wang et al. investigated the dual-rotational configuration for bobbin tool configuration (DBT-FSW). The difference between the dual-rotational configuration in Fig. 1 is the presence of an upper and lower shoulder that can have different rotational speeds or directions. They found that improved material flow effectively prevented the formation of void defects, asymmetric grain sizes, and the fraction of high-angle grain boundaries. The rotational speeds of the shoulder were varied between 400 and 1200 1/min [20].

Generally it can be summarized that previous investigations primarily focused on the interaction between material flow, microhardness, and achievable mechanical weld seam properties. Furthermore, the rotational speeds of shoulder and probe were varied between 219 and $16501 / \mathrm{min}$ so that the investigations considered the following deficits:

I. Development of an adaptable spindle setup provides opposite and equal rotational direction with rotational speeds of up to $40001 / \mathrm{min}$ and $80001 / \mathrm{min}$ for shoulder and probe, respectively.

Previous investigations considered comparatively low rotational speeds so that the influence of increased rational speeds of up to $8000 \mathrm{1} / \mathrm{min}$ remains largely unknown. A constant shoulder and an increased probe rotational speed 
Fig. 2 Two-millimeter EN AA $5754 \mathrm{H} 22$ specimens for the welding experiment and the subsequent mechanical and metallurgical investigations

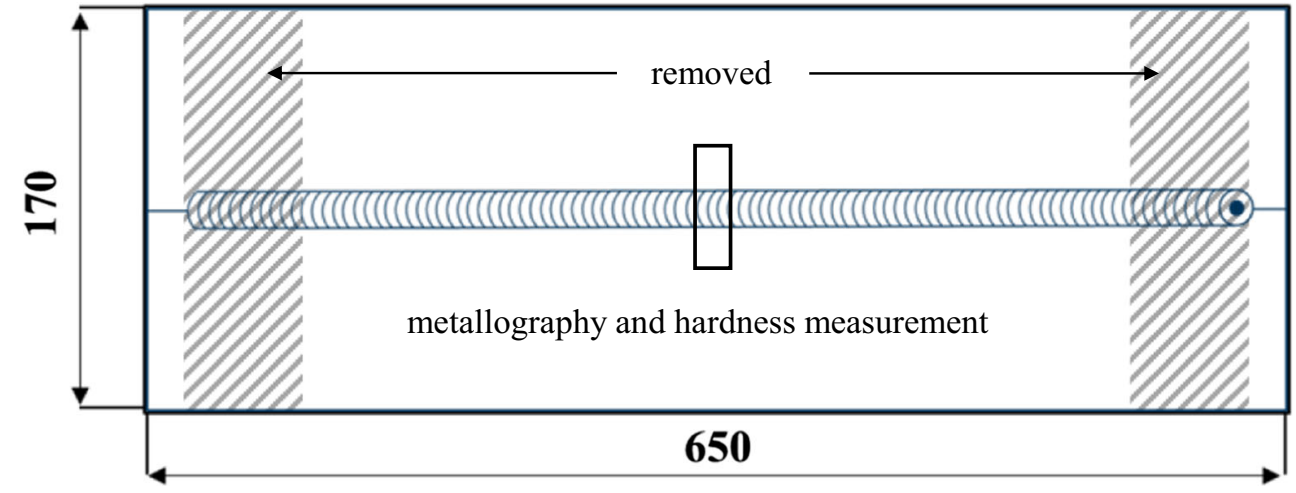

can be used for improved welding penetration depth and an enlarged bonding area on the weld seam root.

II. Characterization of the interactions between process forces, surface quality. and mechanical weld seam properties.

The characterization of the process interactions and the mechanical weld seam properties may be helpful for findings, regarding the variation range of process parameters such as rotation speeds and rotational direction. Furthermore, an opposite rotational direction of shoulder and probe can be used for the reduction of the acting process forces, which affects a loadability decrease for clamping devices.

III. Combination of varying tool configuration such as conventional, stationary shoulder, and dual rotation.

Finally, it was demonstrated that the dual-rotational configuration can be used for combined applications, which generally ensures the advantages of both methods.

\section{Experimental}

The investigations were carried out on EN AA 5754 H22 with 2-mm sheet thickness, $600-\mathrm{mm}$ length, and $170-\mathrm{mm}$ width. The schematic specimen geometry is depicted in Fig. 2. The chemical composition is shown in Table 1.

The welding experiments were performed with a tool configuration from Grenzebach Maschinenbau $\mathrm{GmbH}$ that was developed for stationary shoulder applications. Figure 3 sketches the schematic geometry of shoulder and probe.

Table 1 Composition of EN AA 5754 H111 with a sheet thickness of $8 \mathrm{~mm}$ [21]

\begin{tabular}{lcccccccc}
\hline Element & $\mathrm{Si}$ & $\mathrm{Fe}$ & $\mathrm{Cu}$ & $\mathrm{Mn}$ & $\mathrm{Mg}$ & $\mathrm{Cr}$ & $\mathrm{Zn}$ & $\mathrm{Ti}$ \\
\hline EN AA 5754 & 0.4 & 0.4 & 0.1 & 0.5 & $2.6-3.6$ & 0.3 & 0.2 & 0.15 \\
\hline
\end{tabular}

The shoulder was made of tool steel and had a conical geometry with a diameter of $8 \mathrm{~mm}$. The probe was also manufactured from tool steel, had a conical design and thread for enhanced material flow, and was fixed in a tool holder. The diameter of the shaft and the upper end of the thread was $6 \mathrm{~mm}$ and $3.6 \mathrm{~mm}$, respectively. Furthermore, a gap of $0.5 \mathrm{~mm}$ was adjusted to prevent abrasive contact between shoulder and probe. The length of the thread was $3.3 \mathrm{~mm}$. The plunging depth was set to $95 \%$ of the sheet thickness. In general, all of the welding experiments were performed on a robotized, force controlled FSW setup from Grenzebach Maschinenbau GmbH using a KUKA KR 500 heavy duty robot with an axial force of up to $10 \mathrm{kN}$ and a maximum rotational speed of $14,000 \mathrm{rpm}$. The weld seam production was made with a double spindle construction as depicted in Fig. 4.

The investigations were carried out with a self-fabricated spindle construction that consisted of a primary and secondary component [22]. Detailed information is provided in the following section.

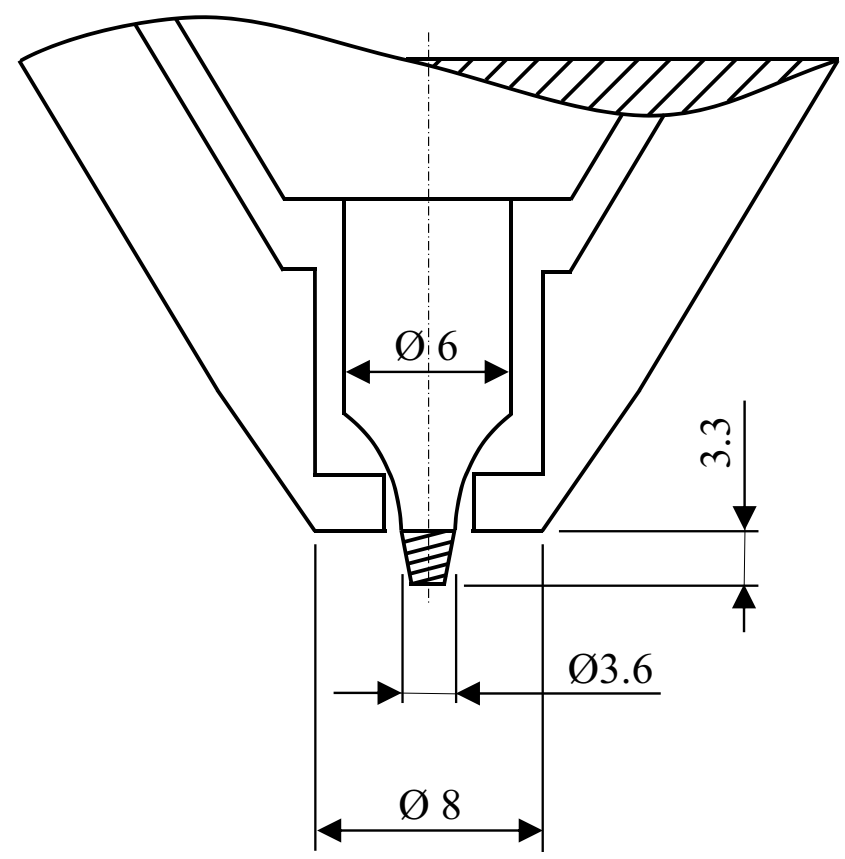

Fig. 3 Tool configuration consists of shoulder and probe 


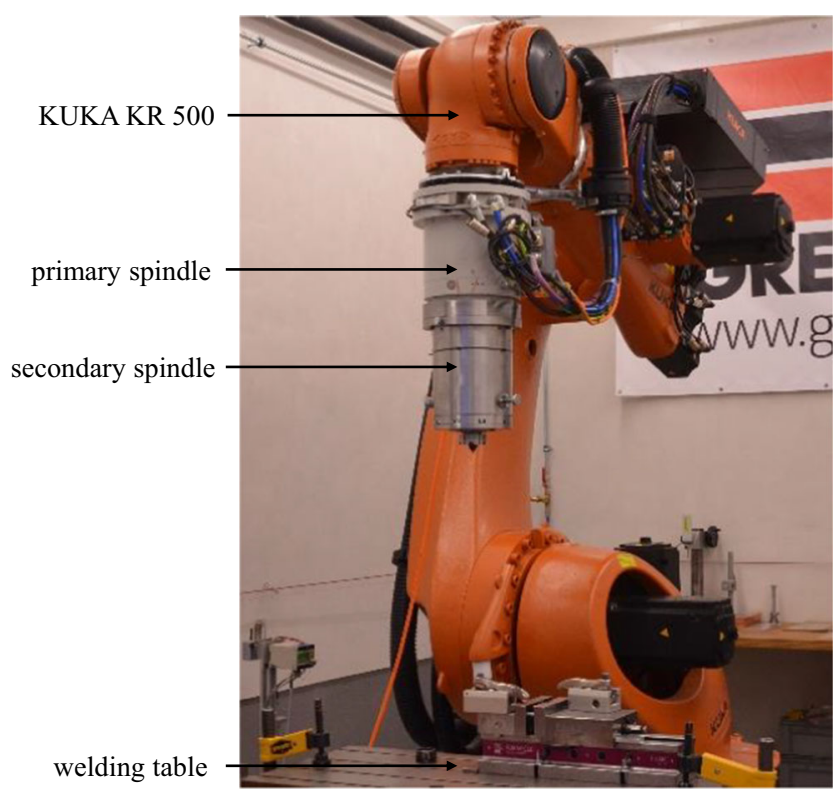

Fig. 4 Robotized FSW setup with double spindle construction consisting of a primary and secondary spindle

The lateral process forces $F_{x}$ and $F_{y}$ were continuously measured with a multi-component dynamometer type $9255 \mathrm{C}$ by Kistler with a maximum scan rate of $50 \mathrm{kHz}$, mounted below the clamping device (Fig. 5). The temperature measurement was carried out at three points at the beginning, center, and end of the weld seam. The characterization with thermocouples type-k was performed along the welding edge, $\mathrm{cf}$. Fig. 10. After the welding experiments, hardness measurements (HV0.5) and both metallography and visual inspections were carried out in accordance with DIN EN ISO 25239-5.

The experiments were conducted at a welding speed of 200 $\mathrm{mm} / \mathrm{min}$, a tilt angle of $2^{\circ}$, in butt joint configuration and repeated two times. For all welding experiments, the shoulder rotational speed was constant at $2500 \mathrm{1} / \mathrm{min}$ and the shoulder rotational direction was equal and opposite to the probe rotational direction. The probe rotational speed was varied between 2500 and $80001 / \mathrm{min}$. The counter-clockwise rotational direction of the probe was kept constant in all experiments to ensure a downward (i.e., in weld root direction) material flow.

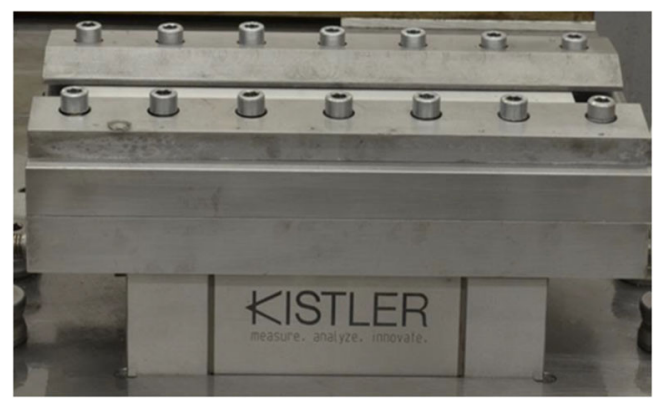

Fig. 5 Clamping technique with multi-component dynamometer for process force measurement

\section{Results and discussion}

\subsection{Development of an adaptable spindle setup}

The experimental investigations were carried out with a selffabricated spindle construction that consisted of a primary and a secondary component. The primary spindle was used to control the rotational speed and rotational direction of the probe. The secondary spindle was connected below the primary spindle and ensured a separate control of shoulder rotational speed and rotational direction. The schematic structure of the secondary spindle is depicted in Fig. 6.

The secondary spindle was connected to the primary spindle by an adapter plate which allowed individual machine integration. The continuous inner shaft was connected to the probe and thus rotational speeds of up to $80001 /$ min with an equal and opposite sense of rotation could be obtained. The difference to the $14,0001 / \mathrm{min}$ can be explained by component imbalances, which may lead to functional damage. In contrast to the probe, the shoulder rotational speed and direction were achieved by an additional servomotor that was connected to the outer shaft. Due to the additional servomotor with a power of $2 \mathrm{~kW}$, it was possible to set a shoulder rotational speed of up to $4500 \mathrm{1} / \mathrm{min}$. Furthermore, water cooling was included to prevent overheating of the secondary spindle. The manual control of the secondary spindle was carried out using the manufacturer's software.

\subsection{Characterization of the interactions between visual inspection, hardness, and process forces}

The following investigations were carried out to investigate the effect of varying rotational direction of the shoulder (equal and opposite to the probe) and increased probe rotational speeds from 2500 to $8000 \mathrm{1} / \mathrm{min}$. The rotational speed of the shoulder, the axial force, and the welding speed were kept constant at $25001 / \mathrm{min}, 2 \mathrm{kN}$, and $200 \mathrm{~mm} / \mathrm{min}$, respectively. The results of the visual inspection are shown in Fig. 7.

Figure $7 \mathrm{a}$ and $\mathrm{b}$ show the weld seam surfaces obtained with equal and opposite shoulder rotational direction. It was observed that visible setup vibrations affected the weld seam surface due to the application of an equal shoulder rotational direction. This can be explained by a higher spindle torque for low rotational speeds and the higher levels' arm caused by the additional secondary spindle. An equal rotational direction of shoulder and probe and a rotational speed of $25001 / \mathrm{min}$ revealed non-homogeneous surface deviations along the entire weld seam length (Fig. 7a). These vibrations can be decreased due to a process force reduction which is achievable due to the usage of lower welding speeds or higher rotational speeds, respectively. The increase of the probe rotational speed from 2500 to $80001 / \mathrm{min}$ shows a significant improvement of the surface conditions (Fig. 7a). Consequently these non- 
Fig. 6 a Spindle stack with adapter plate for adaptive machine integration and $\mathbf{b}$ sectional view with inner and outer shaft

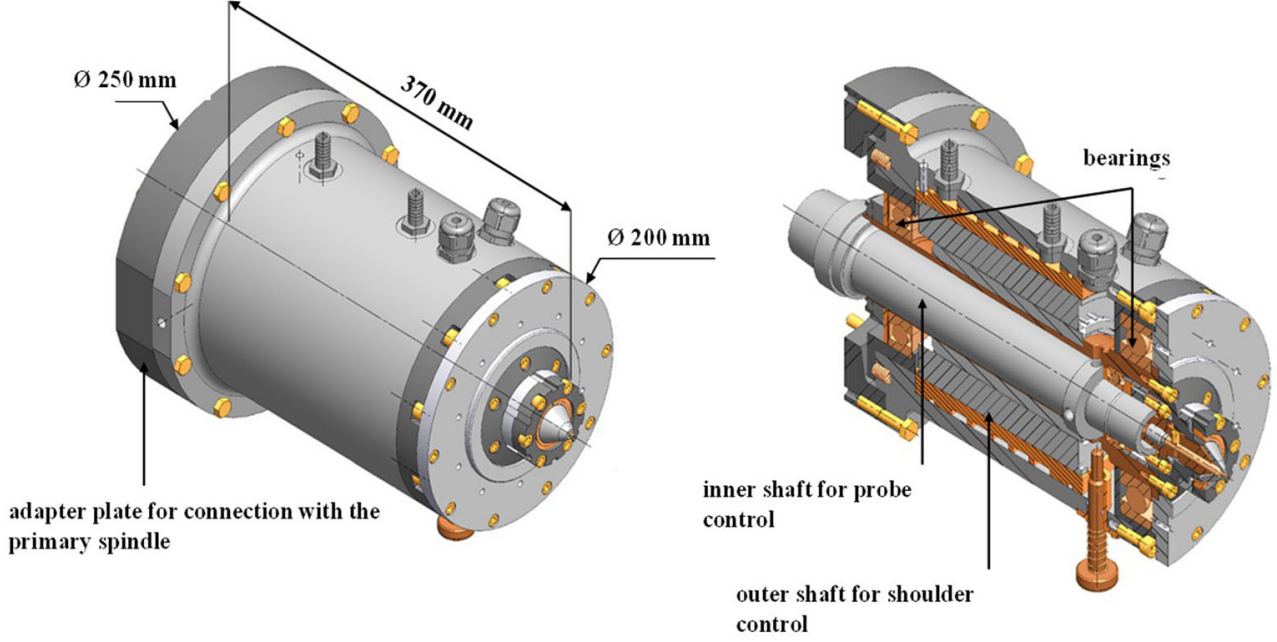

a)

b) homogeneous surface deviations can be completely prevented. Figure $7 \mathrm{~b}$ depicts the weld seam surfaces obtained with an opposite shoulder rotational direction and increased probe rotational speeds. In comparison to the results in Fig. 7a, no visible setup vibration was detected for the opposite shoulder rotational direction. This can be explained by the contrary acting forces from shoulder and probe which bring about a reduction of the lateral forces. In the process force measurement section, a detailed description was carried out. The reduced setup vibrations resulted in homogenous weld seam surfaces over the whole variation range. In summary, it can be noted that the shoulder rotational direction affects the load on the FSW setup and this results in a non-homogeneous weld seam surface. This may be prevented by higher probe rotational speeds by an opposite shoulder rotational direction. Furthermore, Fig. 7b represents almost similar weld seam surfaces even for increasing probe rotational speeds. Consequently it can be expected that higher heat input is achievable without any significant changes on the weld seam surface. In this context a metallographic inspection was
Fig. 7 Visual inspection of the weld seam surfaces with increased probe rotational speeds with $\mathbf{a}$ equal and $\mathbf{b}$ opposite shoulder rotational direction

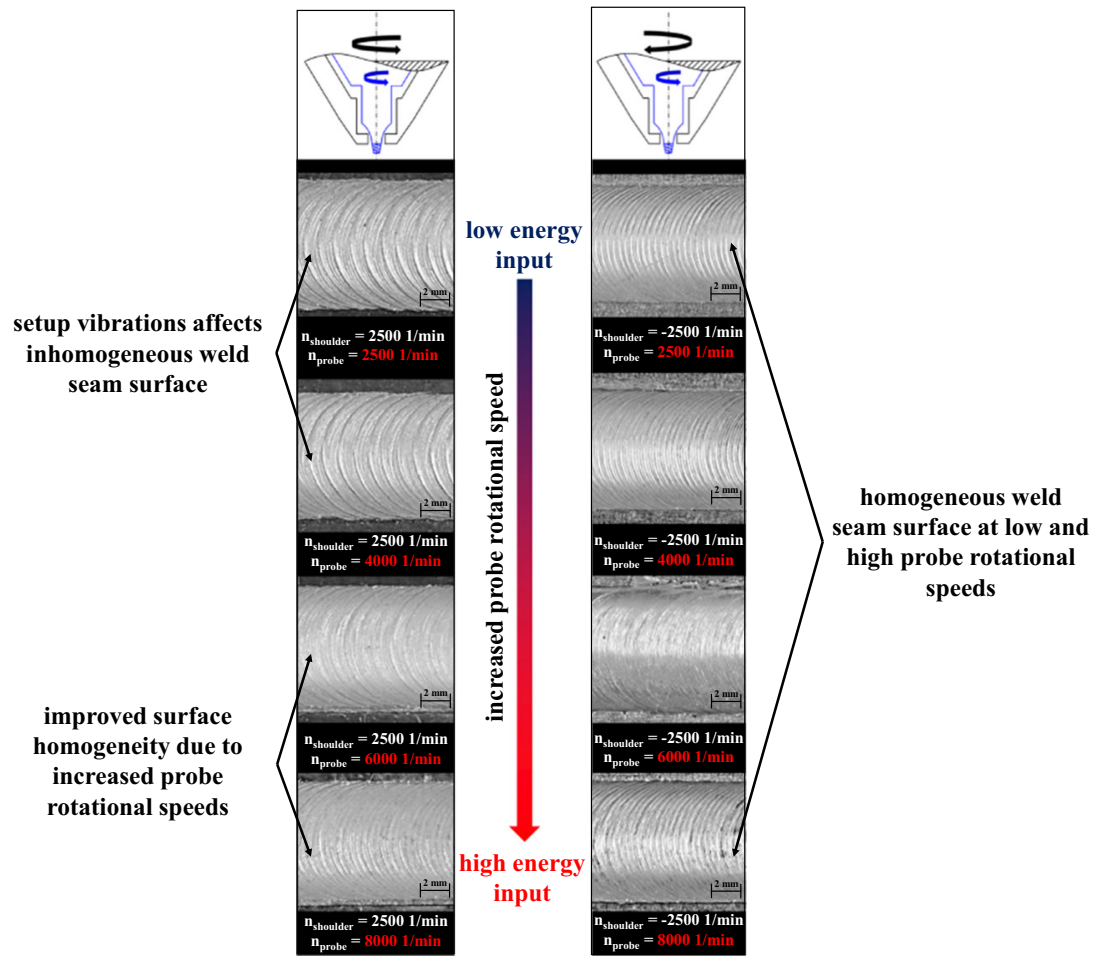

b) 


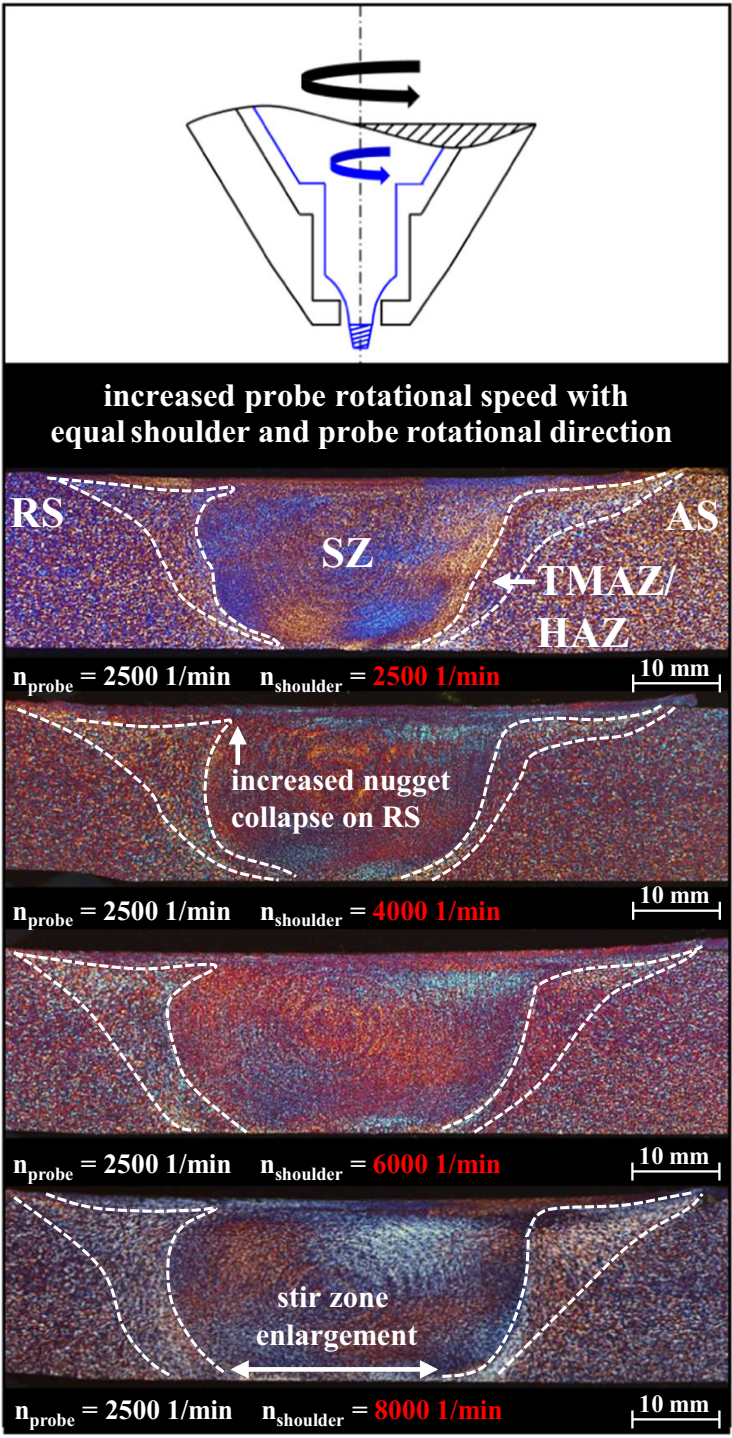

a)

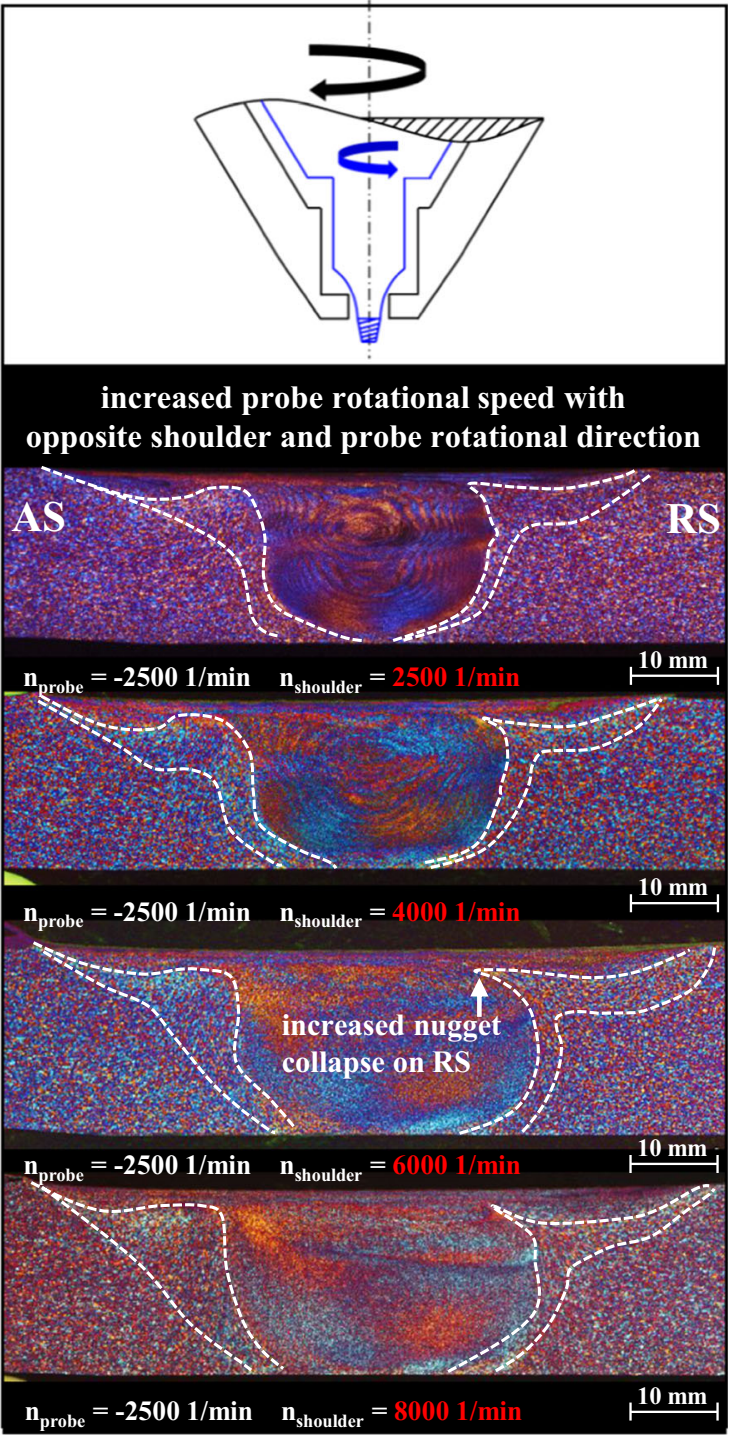

b)

Fig. 8 Metallographical inspection of the weld seam surfaces with increased probe rotational speeds with $\mathbf{a}$ equal and $\mathbf{b}$ opposite shoulder rotational direction

carried out to clarify the influence of shoulder rotational direction and probe rotational speed on the material flow and microstructure.

Figure $8 \mathrm{a}$ and $\mathrm{b}$ depict the results of the metallographic inspection with constant shoulder speed, increased rotational speed of the probe, and various shoulder rotational directions. Furthermore, the characteristic weld seam areas of the stir zone (SZ), the thermomechanically affected zone (TMAZ), and the heat-affected zone (HAZ) are marked with dashed lines. The advancing side (AS) and retreating side (RS) relate to the rotational direction of the shoulder and imply a switch for the opposite rotational direction.

Both Fig. 8a and b show that an increase of the probe rotational speed leads to a significant increase of the stir zone
(SZ) and the heat-affected zone (HAZ/TMAZ). Furthermore, an enlargement of the weld root was observed due to the increased heat input and material displacement. This allows the prevention of irregularities such as incomplete penetration. Furthermore, increased weld penetration depths can be achieved. The comparison of the shoulder rotational directions shows a reduced stir zone width, which can be explained by the opposite material flow of shoulder and probe. Furthermore, it was found that the TMAZ + HAZ show differences between equal and opposite rotational direction of the shoulder. In Fig. 8a and b, the larger TMAZ/HAZ are on the RS and AS. This can be explained by the constant rotational direction of the probe so that the enlargement of the TMAZ/ HAZ can be adjusted by the probe rotational speed. A 
significant nugget collapse (NC) and microstructural inhomogeneities were detected below the weld seam surface. In Fig. $8 \mathrm{a}$ and $8 \mathrm{~b}$, the nugget collapse was found on the RS, which means that the NC is mainly affected by the shoulder rotational direction. The general presence of the $\mathrm{NC}$ is a consequence of slight deviations of the shoulder and probe rotational speeds. The microstructural inhomogeneities caused by the influence of shoulder rotational direction and varying probe rotational speeds are further investigated by hardness measurements.

Figure 9 shows the hardness measurement of the weld seams with equal (Fig. 9a) and opposite (Fig. 9b) shoulder rotational direction and varying probe rotational speeds of up to 8000 1/min (Fig. 9c and d). As can be seen in Fig. 9a- $\mathrm{d}$, the characterization was carried out below the surface, in the center and at the root of the cross-section (dashed lines in black, white and gray).

Figure 9 depicts the results of the hardness measurement for varying shoulder rotational directions and speeds in relation to the measurement range. Furthermore, the hardness of the base material was inserted as dashed line for comparison with the local hardness. Figure $9 \mathrm{a}$ and $\mathrm{b}$ show a hardness increase below the weld seam surface, which can be explained by the fine grain structure and pressure related hardening effects, influenced by the shoulder. In the center of the weld seam, an approximately constant hardness was detected similar to the base materials. Only in the area of the SZ is a slight increase in hardness obtained, which can be explained by the
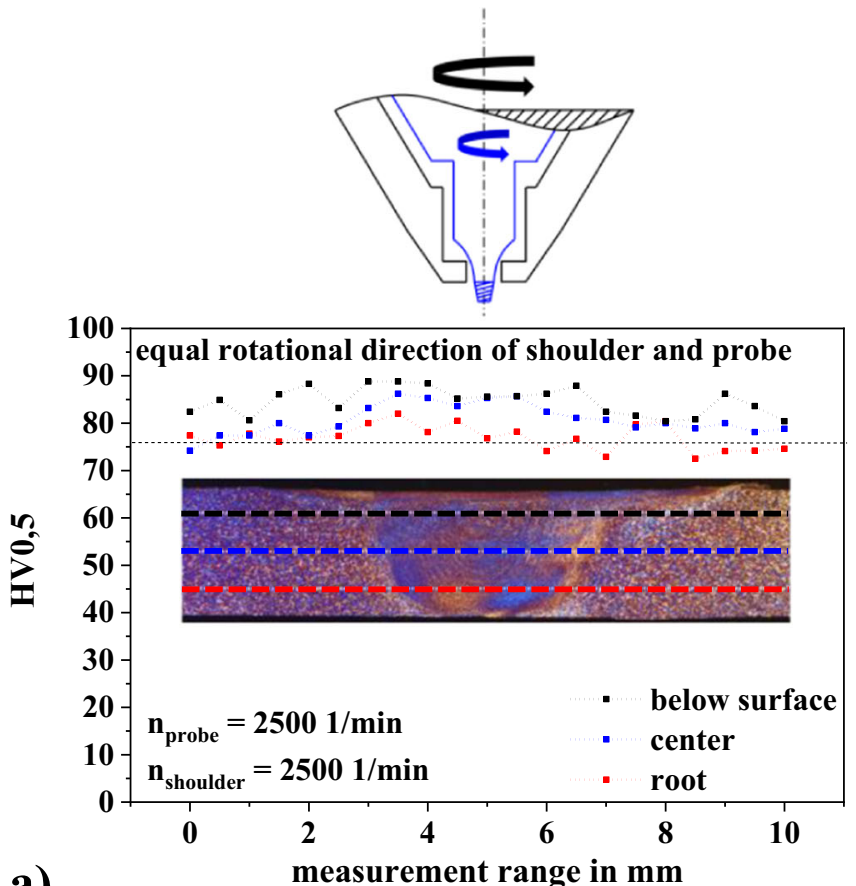

a)

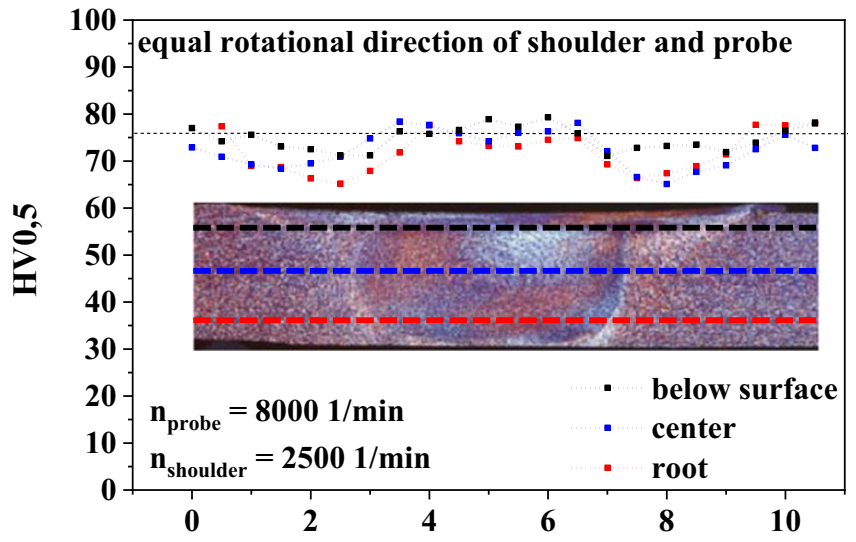

c) measurement range in $\mathrm{mm}$
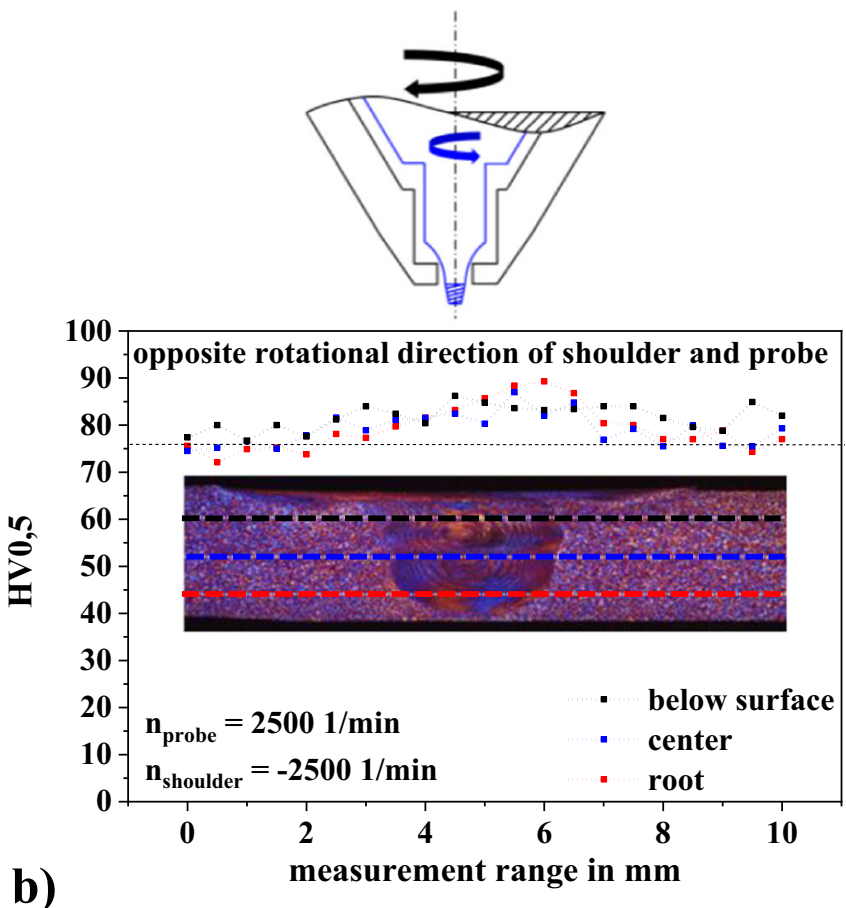

b)

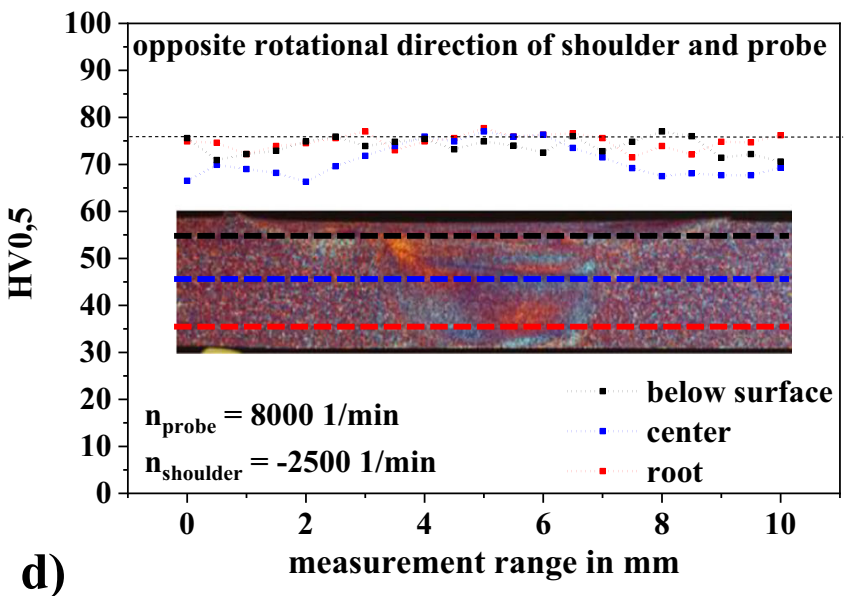

Fig. 9 Hardness measurement of the weld seams with $\mathbf{a}$ equal and $\mathbf{b}$ opposite shoulder rotational direction (2500 $1 / \mathrm{min})$ and $\mathbf{c}$ and $\mathbf{d}$ varying probe rotational speeds of up to $8000 \mathrm{1} / \mathrm{min}$ 
recrystallized fine grain structure. In Fig. 9c and d, the probe rotational speed was increased up to $80001 / \mathrm{min}$. Here the hardness decreased by $10 \%$ from 76 to $65 \mathrm{HV}$ in the area of TMAZ and HAZ. In the stir zone the hardness increased to 76 $\mathrm{HV}$, which is in the range of the base material. However, in Fig. $9 \mathrm{c}$ the hardness decrease is more pronounced than in the case of opposite shoulder rotational direction (Fig. 9d). This can be explained by improved material intermixing in which an increasing homogenization of the microstructure is achieved. Further tensile tests were carried out to investigate the strength of failure properties.

To investigate the heat input due to the variation of the shoulder rotational direction and varying probe rotational speeds, temperature measurement were carried out in the SZ. The thermocouples type-k were implemented at three positions to measure the temperature at the beginning (measurement point $1-25 \mathrm{~mm}$ ), center (measurement point 2-150 $\mathrm{mm}$ ), and end of the weld seam (measurement point 3-250 $\mathrm{mm}$ ). Figure 10 shows the geometry and the position of the thermocouples. The temperature measurements were repeated two times.

Figure 11 shows the results of the temperature measurements at the beginning, center, and end of the weld seam for varying shoulder rotational directions and increased probe rotational speeds. The rotational speed of the shoulder, the axial force, and the welding speed were kept constant at 2500 $1 / \mathrm{min}, 2 \mathrm{kN}$, and $200 \mathrm{~mm} / \mathrm{min}$, respectively.

Figure 11a and b show the results of the temperature measurement starting with low (2500 1/min — black squares) and high (8000 1/min - light gray squares) probe rotational speeds. Using the equal rotation direction of shoulder and probe, an increasing temperature at measurement points 1-3 was detected. The highest temperature of about $580{ }^{\circ} \mathrm{C}$ was observed at measurement point 3 for a probe rotational speed of $8000 \mathrm{l} / \mathrm{min}$. For a probe rotational speed of $2500 \mathrm{1} / \mathrm{min}$, an almost constant mean temperature in the range of $450{ }^{\circ} \mathrm{C}$ was detected for equal and opposite rotational direction. Only the opposite rotational direction at point 2 depicts an average temperature of approx. $500{ }^{\circ} \mathrm{C}$. That can be explained by inaccuracies during the temperature measurement. However, the application of higher probe rotational speed exhibits an increased temperature for all measurement points. The increase of the probe rotational speed from 2500 to $80001 /$ min brings about an increase of the mean temperature of up to $130 \mathrm{~K}$ at measuring point 3 (compare Fig. 11a). In the case of an opposite rotational direction of shoulder and probe (Fig. 11b), an increasing mean temperature was obtained at all measuring points. The highest average temperature of $605^{\circ} \mathrm{C}$ was detected at measurement point 3. Similar to Fig. 11a, a probe rotational speed of $2500 \mathrm{1} / \mathrm{min}$ exhibited an almost constant temperature in the range of $450{ }^{\circ} \mathrm{C}$ between measuring points 1 and 3. Only at measuring point 2 was a slight temperature increase of up to $480{ }^{\circ} \mathrm{C}$ observed. A further increase of the probe rotational speed exhibited an increased temperature for all measurement points. The highest temperature difference of up to $135 \mathrm{~K}$ was detected at measurement point 3 . A comparison of Fig. 11a and $\mathrm{b}$ shows higher temperatures for the opposite shoulder rotational direction. This can be explained by the increased material deformation and the opposite material flow direction. However, this effect occurs at higher probe rotational speeds of about $8000 \mathrm{1} / \mathrm{min}$. Lower probe rotational speeds show only marginal temperature differences.

Finally, process force measurements were carried out to investigate the interactions between welding setup, tool configuration, and workpiece. Figure 12 shows the process forces for equal (Fig. 12a) and opposite (Fig. 12b) shoulder rotational direction and varying probe rotational speeds of up to $8000 /$ $\min$ (Fig. 12c and d).

Figure 12 depicts the results of the process force measurements for varying shoulder rotational directions and speeds as a function of welding time. The dark and light gray lines represent the forces $F_{x}$ and $F_{y}$ which act along and beside the welding direction, respectively. The forces are smoothed with a FFT-Filter to remove noisy oscillations from the setup
Fig. 10 Geometry of the temperature measurement and position of the thermocouples

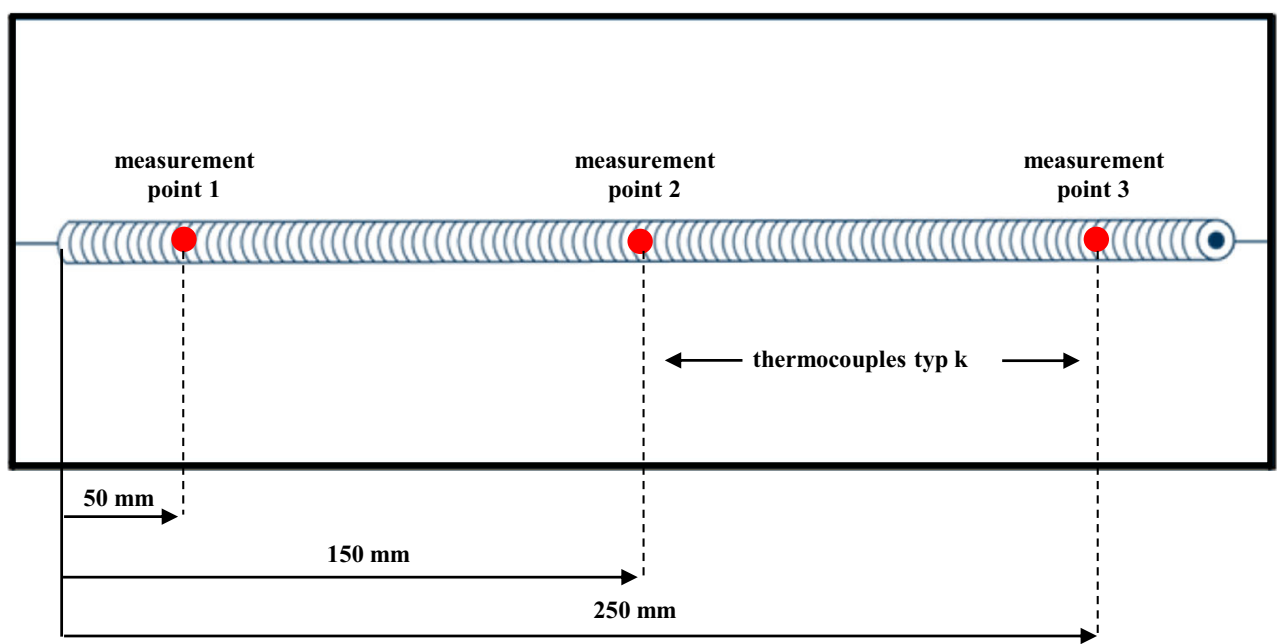


Fig. 11 Temperature measurement of the specimens with increased probe rotational speeds with a equal and $\mathbf{b}$ opposite shoulder rotational direction
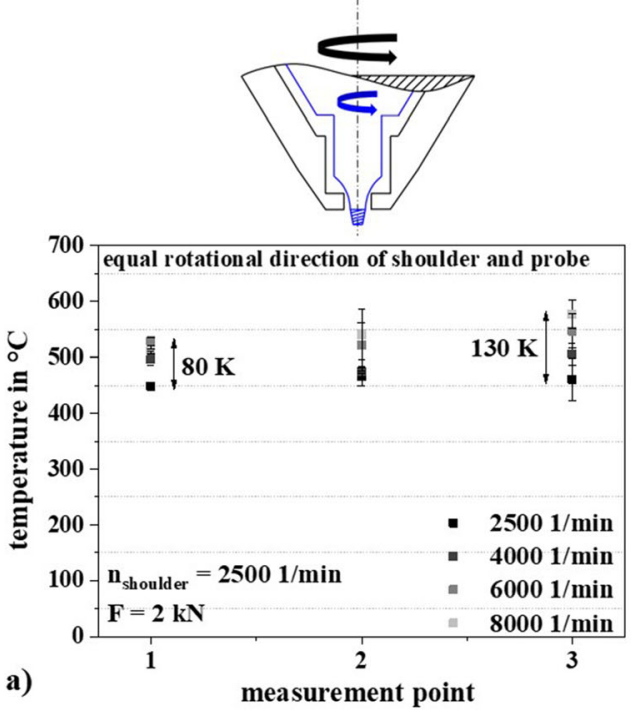
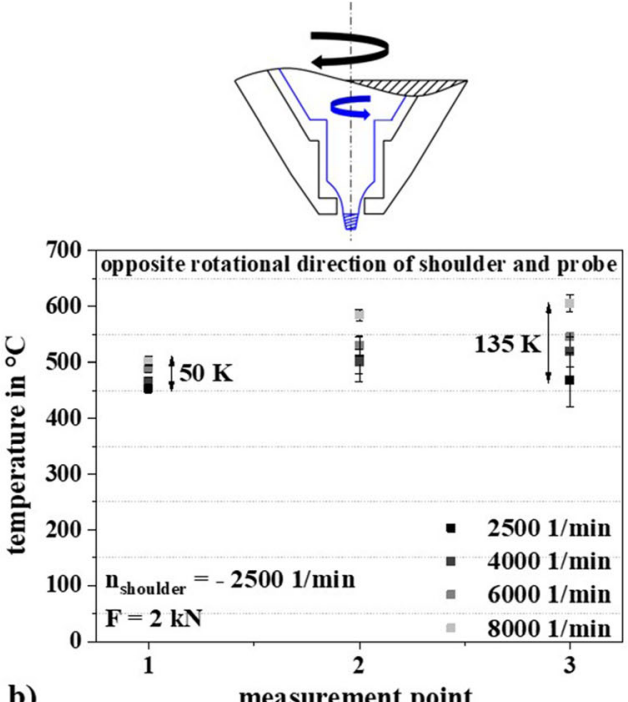

b)

interval of tool plunging $(<30 \mathrm{~s})$ is not considered. Similar rotational speeds of $2500 \mathrm{1} / \mathrm{min}$ with equal and opposite and detect the average value of the forces. The results are evaluated only for the welding phase ( $>30 \mathrm{~s})$. The time
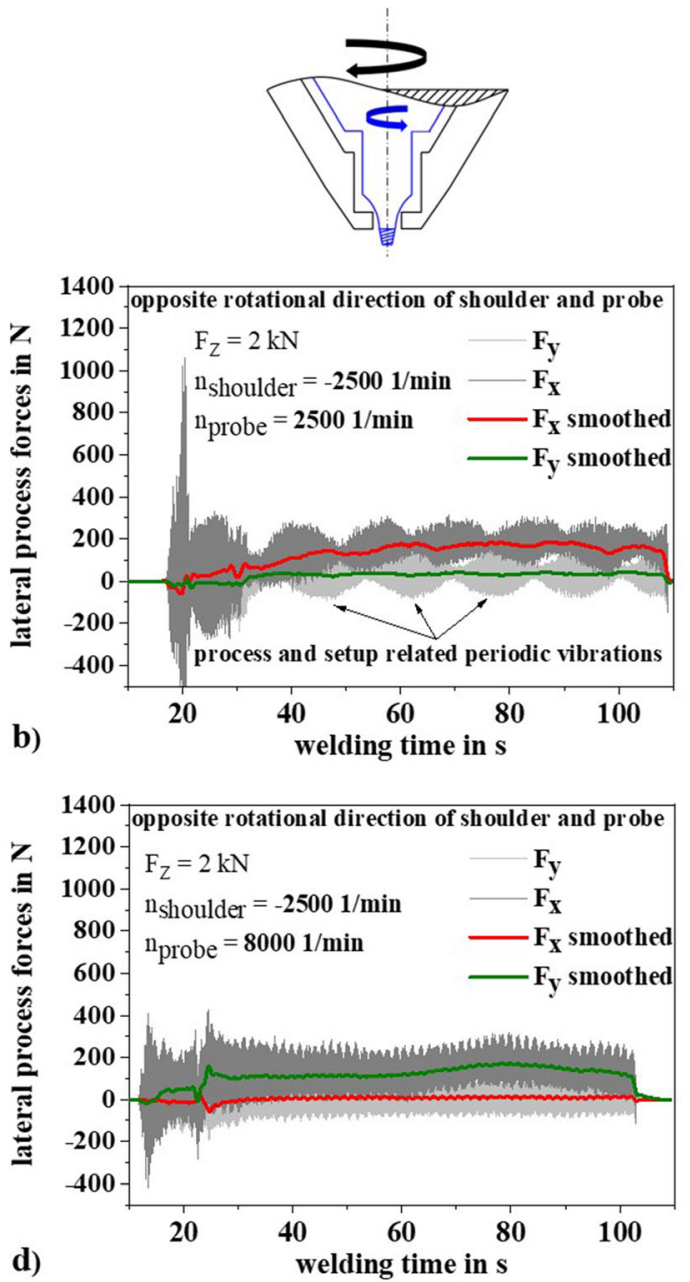

Fig. 12 Lateral process forces $\mathrm{F}_{\mathrm{x}}$ and $\mathrm{F}_{\mathrm{y}}$ of constant probe rotational speeds and $\mathbf{a}$ equal and $\mathbf{b}$ opposite shoulder rotational direction. Increased probe rotational speeds of up to $8000 \mathrm{1} / \mathrm{min}$ with $\mathbf{c}$ equal and $\mathbf{d}$ opposite shoulder rotational direction 
rotational direction of shoulder and probe show an average $F_{x}$ of $200 \mathrm{~N}$. However, a significant increase of the $F_{x}$ amplitude of up to $800 \mathrm{~N}$ was only found for the equal rotational shoulder direction (compare Fig. 12a). Compared to the opposite rotational direction in Fig. 12b, the amplitude of $F_{x}$ varies in a range of $200 \mathrm{~N}$. This can be explained by interference effects between the $F_{x}$ forces, which originate separately from shoulder and probe. The average process force $\mathrm{F}_{\mathrm{y}}$ oscillated about the zero point for equal and opposite tool configurations. However, the amplitudes vary between $400 \mathrm{~N}$ for equal and $200 \mathrm{~N}$ for opposite rotational direction of the shoulder.

In summary, the amplitudes of $F_{x}$ and $F_{y}$ exhibited a loss by a factor of 4 and 2, respectively, which explained the setup vibrations discussed above (compare Fig. 7). An increased probe rotational speed of up to $80001 / \mathrm{min}$ (Fig. $12 \mathrm{c}$ and d) revealed a significant reduction of the $F_{x}$ and $F_{y}$ amplitudes. In both cases, $\mathrm{F}_{\mathrm{x}}$ is about $180 \mathrm{~N}$ and $\mathrm{F}_{\mathrm{y}}$ oscillated around the zero point on average. Further detailed experiments are carried out to clarify the interactions between the acting forces, setup vibrations, and weld seam properties. This includes in particular a deep and separate characterization of the vibrations caused by the FSW setup and welding tool.

\subsection{Combination of varying tool configuration}

In order to demonstrate the variety of applications for the adaptable spindle setup, the combination of stationary and dual-rotational configuration was carried out on the $2-\mathrm{mm}$ EN AA $5754 \mathrm{H} 22$ sheets. The dual-rotational configuration allows the realization of a high heat input (compare Fig. 8) with a large bonding area on the weld seam root. The stationary shoulder configuration ensured superior mechanical weld seam properties such as the tensile and fatigue strength. Figure 13 shows the weld seam surface, initially joined with stationary shoulder and subsequently during running process with the dual-rotational configuration.

The combined application of stationary shoulder and dual-rotational configuration was performed with a welding speed of $200 \mathrm{~mm} / \mathrm{min}$ and an axial force of $2000 \mathrm{~N}$. The weld seams manufactured with stationary shoulder and dual-rotational configuration required a probe rotational speed of $4500 \mathrm{1} / \mathrm{min}$. The shoulder rotational speed was $25001 / \mathrm{min}$, opposite to the probe rotational direction. Thus, the combination of stationary shoulder and dual rotation was used to demonstrate the advantages of both tool configurations.

\section{Conclusions}

The aim of this study was to demonstrate a method for the advanced usage of friction stir welding by separate control of shoulder and probe. This was done using a compact and adaptive setup that consisted of a primary and secondary spindle. The separate control of shoulder and probe allowed a significant adjustment of the heat input, the reduction of process forces, and the application of varying tool configurations such as conventional, stationary shoulder and dual rotation. The investigations were performed on EN AA5754 sheets with a thickness of $2 \mathrm{~mm}$. The following conclusions could be drawn:

- An adaptable spindle setup was first developed for separate control of shoulder and probe. The maximum rotational speed of shoulder and probe was $40001 / \mathrm{min}$ and $80001 / \mathrm{min}$, respectively. The secondary spindle was connected to the primary spindle by an adapter plate, which ensured an individual machine integration.

- In the case of equal shoulder rotational direction, the enlargement of the primary spindle significantly affected the FSWsetup vibrations, which lead to non-homogeneous weld seam surfaces. Due to the increase of the probe rotational speed, the visual vibrations were completely eliminated.

- The application of an opposite rotational direction of shoulder and probe exhibited similar weld seam surface properties over the whole variation range. As a consequence, the heat input generated by the probe did not affect the surface conditions and prevented local melting on the shoulder edges.

- Constant shoulder and increased probe rotational speeds may be used for the modification of the joining area. Increase probe rotational speed ensured an enlargement of the displaced material on the weld seam root so that the prevention of irregularities such as insufficient penetration was achieved.
Fig. 13 Surface of the weld seam manufactured with combined tool configuration of stationary shoulder and dual rotation
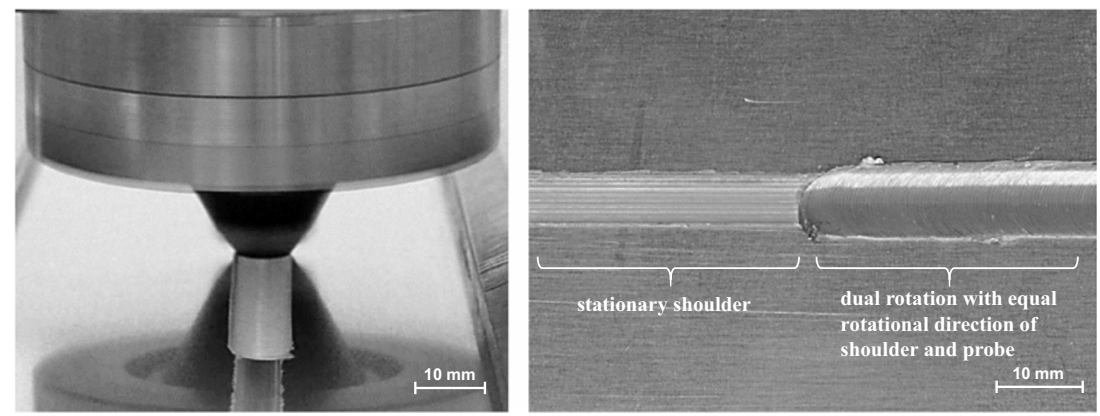
- The usage of opposite rotational direction of shoulder and probe exhibited a homogeneous microstructure compared to the equal rotational direction.

- The amplitudes of the process forces could be reduced by a factor of 4 by using an opposite rotational direction of shoulder and probe. As a consequence, a decrease of the loads acting on FSW setup and welding tool was achieved.

- The combined application of varying tool configurations during the welding process was successfully demonstrated by stationary shoulder and dual rotation with equal rotational direction of shoulder and probe. Thus, the advantages of varying tool configurations could be realized with a compact spindle stack.

Acknowledgements The IGF Project No. 19.566 BG of the research association "Schweißen und verwandte Verfahren e.V." of the DVS, Aachener Straße 172, 40223 Düsseldorf, was acknowledged, on the basis of a resolution of the German Bundestag, promoted by the Federal Ministry for Economic Affairs and Energy via AiF within the framework of the program for the promotion of joint industrial research and development (IGF). The authors thank Michael Hasieber and the industrial participants, in particular Dr. Weigl, for funding and support.

Funding Open Access funding enabled and organized by Projekt DEAL.

Open Access This article is licensed under a Creative Commons Attribution 4.0 International License, which permits use, sharing, adaptation, distribution and reproduction in any medium or format, as long as you give appropriate credit to the original author(s) and the source, provide a link to the Creative Commons licence, and indicate if changes were made. The images or other third party material in this article are included in the article's Creative Commons licence, unless indicated otherwise in a credit line to the material. If material is not included in the article's Creative Commons licence and your intended use is not permitted by statutory regulation or exceeds the permitted use, you will need to obtain permission directly from the copyright holder. To view a copy of this licence, visit http://creativecommons.org/licenses/by/4.0/.

\section{References}

1. Chien JM, McKinstry KC; Baek C, Horvath A, Dornfeld D (2012) Multi-objective analysis on joining technologies, leveraging technology for a sustainable world, 19th CIRP international conference on life cycle engineering May 23-25 , Berkeley, pages 287-292, https://doi.org/10.1007/978-3-642-29069-5_49

2. Gierth M, Henckell P, Ali J, Scholl J, Bergmann JP (2020) Wire arc additive manufacturing (WAAM) of aluminum alloy AlMg5Mn with energy-reduced gas metal arc welding (GMAW). Materials 13:2671, pages 1-22. https://doi.org/10.3390/ma13122671

3. Mishra RS, Kumar N (2014) Friction stir welding and processing-, Science and engineering. Springer, Cham, pp 1-338 ISBN: 978-3319-07042-1

4. Kumar N, Mishra RS, Baumann JA (2014) Residual stresses in friction stir welding, first edn. Elsevier Butterworth-Heinemann, pp 1-60 ISBN; 978-0-12-800150-9

5. Lohwasser D, Chen Z (2010) Friction stir welding: from basics to applications. Woodhead Publishing Limited, Cambridge, pp 1-436 ISBN: 978-1845694500
6. Grätzel M, Regensburg A, Hasieber M, Gerken JA, Schürer R, Bergmann JP (2019) Scaling effects during friction stir welding of aluminum alloys with reduced tool aspect ratios. Weld World 63:337-347. https://doi.org/10.1007/s40194-018-0666-7

7. Hasieber M, Grätzel M, Bergmann JP (2020) A novel approach for the detection of geometric- and weight-related FSW tool wear using stripe light projection. J Mater. Manuf. Process 4:60, pages 1-20. https://doi.org/10.3390/jmmp4020060

8. Kashaeva N, Ventzkea V, Çamb G (2018) Prospects of laser beam welding and friction stir welding processes for aluminum airframe structural applications. J Manuf Process 36:571-600. https://oi. org/10.1016/j.jmapro.2018.10.005

9. Weigl M, Grätzel M, Bergmann JP (2019) Technological progress in stationary shoulder friction stir welding of aluminum alloys. journal of light metal Welding:60-64. https://doi.org/10.11283/ jlwa.58.60s

10. Weigl M, Grätzel M; Gerken JA, Bergmann JP (2018) Stationary shoulder tools for long-term loading under industrial conditions, Proceedings of 12 th international symposium on friction stir welding, Chicoutimi, Canada, 26-28

11. Chehreh AB, Grätzel M, Bergmann JP, Walther F (2020) Effect of corrosion and surface finishing on fatigue behavior of friction stir welded EN AW-5754 aluminum alloy using various tool configurations. Materials 13:14, pages 1-20. https://doi.org/10.3390/ ma13143121

12. Regensburg A, Schürer R, Weigl M, Bergmann JP (2018) Influence of pin length and electrochemical platings on the mechanical strength and macroscopic defect formation in stationary shoulder friction stir welding of aluminium to copper. Metals 8:85, pages 19. https://doi.org/10.3390/met8020085

13. Grätzel M, Hasieber M, Löhn T, Bergmann JP (2020) Reduction of friction stir welding setup loadability, process forces and weld seam width by tool scaling. Proc. Inst. Mech. Eng. L 234(5):1-10. https:// doi.org/10.1177/1464420720903331

14. Chen Y, Li H, Wang X, Ding H, Zhang F (2019) A comparative investigation on conventional and stationary shoulder friction stir welding of Al-7075 butt-lap structure. Metals 9:12, pages 1-12. https://doi.org/10.3390/met9121264

15. Vicharapu B, Liu H, Fujii H, Narasaki K, Ma N, De A (2020) Probing residual stresses in stationary shoulder friction stir welding process. Int J Adv Manuf Technol 106:1573-1586. https://doi.org/ 10.1007/s00170-019-04570-9

16. Li JQ, Liu HJ (2013) Design of tool system for the external nonrotational shoulder assisted friction stir welding and its experimental validations on 2219-T6 aluminum alloy. Int J Adv Manuf Technol 66:623-634. https://doi.org/10.1007/s00170-012-4353-3

17. Shi L, Wu CS, Liu HJ (2014) Numerical analysis of heat generation and temperature field in reverse dual-rotation friction stir welding. Int J Adv Manuf Technol 74:319-334. https://doi.org/10.1007/ s00170-014-5967-4

18. Thomas WM, Norris IM; Staines DG, Watts E (2005) Friction stir welding - process developments and variant techniques, The SME summit 2005 Oconomowoc, Milwaukee, USA

19. Montazerolghaem H, Badrossamay M, Tehrani AF, Rad SZ, Esfahani MS (2014) Dual-rotation speed friction stir welding: experimentation and modeling. Mater Manuf Process:1109-1114. https://doi.org/10.1080/10426914.2014.973578

20. Wang FF, Li WY, Shen J, Wen Q, dos Santos JF (2018) Improving weld formability by a novel dual-rotation bobbin tool friction stir welding. J Mater Sci Technol 34(1):135-139. https://doi.org/10. 1016/j.jmst.2017.11.001

21. DIN EN 573-3:2013-12 (2013) Aluminium und Aluminiumlegierungen - Chemische Zusammensetzung und Form von Halbzeug - Teil 3: Chemische Zusammensetzung und Erzeugnisformen; Deutsche Fassung EN 573-3:2013, 1-30 